\title{
Features of blood supply to the arteries of the forelimb of the northern domesticated reindeers
}

\author{
Mikhail Potapov, Konstantin Nifontov*, and Aleksey Belogurov \\ Yakut State Agricultural Academy, 677007 Yakutsk, Russia
}

\begin{abstract}
A role of the blood circulatory system in a regulation of organism's physiological functions and in a development of pathological processes is enormous. In this work the specifics of the vascular supply of the northern reindeer's limbs are presented which are characterized by monotonous scheme. However, the northern reindeer has anatomic specific due to advanced second and the fifth dactyls. In this article there is determination of the development of forelimb's arterial vessels of the northern reindeer during postnatal ontogenesis. In the postnatal period of development, the most intensive growth in the length and diameter of the great arteries is observed in the first year of the animal's life, especially in the first month.
\end{abstract}

\section{Introduction}

The development of agriculture within the conditions of the Extreme North makes reindeer husbandry perspective approach. Comprehensive studying of the structure and the development of the northern reindeers may contribute to the development of reindeer husbandry. On practice veterinary specialists often encounter with diseases of limbs which have infectious and non-infectious etiology basis. For effective maintenance of medical, diagnostic and preventive arrangements specialists have to apply knowledge on regularity of aging changes on the systems of organs and structures of the northern reindeers [1-3]. Currently there are not enough researches on arterial vascularisation of thoracic limb.

The purpose of the work is to study anatomical and morphometric characteristics of arterial vessels of thoracic limbs during postnatal ontogenesis on different gender and age groups.

\section{Materials and methods of the research}

The objects of the research are carcass of the northern reindeers on different age groups (1 month, 6 months, 12 months, 3 years, 5 years, 10 years) -3 heads of reindeers for each age group that are taken from different reindeer husbandry managements in the Republic of Sakha (Yakutia). All materials are received from clinically healthy animals. The age was determined on the basis of survey of zoo veterinary specialists, experienced regional reindeer herders and veterinarians. There were selected left and right limbs of animals, both genders $[1,4]$.

The definition of morphologic characteristics of thoracic limb arteries was determined as following artery underwent aqueous composition and $5 \%$ of gelatin, red color dye (G.M. Iosifov, 1904) and it was inserted by syringe through artery axillaris then it was dissected and measured by line and ocular micrometer (division $0,1 \mathrm{~mm}$ ). Wall thickness of arteries was found on histo cuts that were dyed by haematoxylin-eosin [1].

\section{Results and discussion}

Arteria axillaris is beside of axillary vein. It reaches caudal edge of scapula which is by teres major muscle gives arteria axillaris and gives to arteria subscapularis. It is going by caudal edge of blade up and then it gives branches to the back side of teres major muscle and the broadest muscle of back and deeper chest muscles (it is going with the vein which is with vena axillaris (chest dorsal arteria). The length of arteries in comparison with newborn calves increases by 2.9 times and the diameter of arteries grows by 1.9 times (table 1 ).

Arteria subscapularis goes up alongside caudal edge of subscapular muscle on medial surface of caput longum of triceps, from the medial side it is covered by caudal edge of subscapularis muscle and teres major muscle. On the level of scapula's middle it rarely bends on lateral surface. In infraspinatous fossa arteria goes in the transverse direction and continues as circular scapular arteria. During postnatal ontogenesis the length of arteria in comparison with newborn calves increases by 2.4 times and diameter of arteria grows by 2.1 times (table 1).

Arteria acromialis is directed to cephalic side. First it goes with vein that reaches subscapularis muscle. Then it transfer to medial surface of subscapular muscle of the neck of scapula. It gives small branches to subscapular muscle. In the middle of subscapular muscle there are 2 branches: proximal and distal. Proximal branch goes up between transversus muscle and subscapular muscle. Together with them there go subscapular nerve and vena

* Corresponding author: kosnif@yandex.ru 
acromialis which are directed to distal end of chuck tender. The distal branch is thinner and it is directed down to the lower end of chuck tender. The length of arteries out of ontogenesis period lengthen by 13.5 times and diameter of arteries increases by 11.3 times (table 1 ). Dorsal mammal arteria (a. thoracica dorsalis) leaves arteria subscapularis near with its beginning in caudal direction against arteria acromialis branch. Dorsal it is accompanied with same-named nerve where it branches out in the wide muscle of the back. Besides it gives branches in axillary lymph nodes and little branches in big round muscle - to the long head of triceps. The length of arteria during postnatal period of the development in comparison with newborn calves increases by 2.4 times and the diameter of arteria grows by 1.8 times (table 1 ).

Arteria brachialis is directed down along caudal edge of subdermal-brachialis muscle to the middle of humerus and then it goes between bicipital and medial head of triceps. It crosses medial surface of the shoulder and goes between coracobrachial muscle and medial head of triceps brachii muscle. Then it appears under fascia near with caudal edge of the biceps brachii in the elbow region. During postnatal period of animal's development the length of arteria in comparison with newborn calves increases by 1.9 times and diameter grows by 2.0 times (table 1). Further the arteria brachialis after of its separation from arteria interossea communis goes into arteria mediana.

Medial circumflexa brachialis arteria. It separates from arteria brachialis underneath of separation list of profunda brachii arteria. With the arteria of biceps it forms general trunk and then it goes further and up between subdermal brachial and biceps muscles. During postnatal ontogenesis the length of arteries increases by 2.3 times and diameter grows by 1.9 times (table 1 ).

Arteria of biceps brachii separates from general trunk which is formed by cranial circumflexa brachialis arteria. Sometimes it separates from Brachialis arteria as independent branch at a right angle from cranial circumflexa brachialis arteria and it enters into biceps muscle. After the birth of animals the length of arteries in comparison with newborn calves increases by 2.6 times and diameter of arteria grows by 2.2 times (table 1 ).

Collateral arteria ulnaris separates backwards from arteria brachialis. Distal block of humerus goes down with vein on cranial edge of medial head of triceps brachii muscle and goes to medial surface of elbow joint and together with vein it enters sinews. The end point of the long head of triceps brachii muscle gives branches to long and medial heads of triceps brachii muscle, to tensor fasciae of forearm. During postnatal period of ontogenesis in comparison with newborns the length of arteries increases by 2 times and diameter by 2.6 times.

Collateral arteria radialis separates from arteria brachialis proximal from elbow joint to lateral side - it goes between biceps muscles, inner brachialis muscles and radial flexor muscle of wrist. It gives branches to: biceps muscle, inner brachialis muscle and radial flexor muscle of wrist. One branch separates between biceps muscles and inner brachial muscle on dorsal surface of forearm with same-named vena and nerve. Then they go amongst superficial (subdermal) vein of the forearm. After the birth of reindeer the length of arteries in comparison with newborn calves increases by 1.6 times and the diameter of arteria grows by 2.4 times.

Distal part of arteria brachialis. From distal part gives 2 branches in elbow joint. 1 - branch to the biceps brachii; 2 - big branch to wrist and to deep finger flexor, this branch goes to the small body of elbow flexor of wrist and to the deep finger flexor. Then it anastomoses with arteria mediana the distal part of arteria brachialis which is accompanying 2 branches: the first is on palmar side of vena; on front is median nerve and anastomosis of collateral and radial veins.

Arteria interossea communis separates from arteria brachialis to arteria interossea communis. On the beginning of arteria interossea there are two muscular branches in humeral heads of deep finger flexor. The second separates to very thin collateral branch.

Arteria mediana is direct continuation of arteria brachialis, after its separation from arteria interossea communis. It distally goes down alongside medial border of radial bone. In the region of proximal half of forearm it is covered by only the fascia. On the lower half of the forearm arteria mediana is slightly moved more medial and there it is covered by the masses of muscles of wrist and fingers flexors. During postnatal period of ontogenesis in comparison with the newborn calves the length increases by 1.9 times and diameter grows by 2.1 times (table 1).

Proximal part of it is covered by radial flexor of wrist and then it goes alongside medial border of tendons of superficial and deep finger flexors. On the middle of the body of radial bone it separates medial-radial arteria in the region of middle carpal joint together with median nerve it reaches communis Palmaris carpal copula. Then it goes on medial border of articular surface of finger's flexors as palmar superficial metacarpal arteria.

Medial-radial arteria separates on the level of the middle of the radial bone's body and from arteria mediana it goes down. It is covered by radial wrist flexor and then in appears near with arteria mediana. In distal radial bone it separates from arteria mediana and nerve. It is accompanied with vein which is separate from collateral radial vena. Further it goes under of fascia and skin, then it goes on medial surface of wrist accompanied with adventive saphenous vein of forearm and on the top edge of metacarpus it gives branches to wrist joint. Then it reaches the deep palmar metacarpal arteria. During postnatal period of ontogenesis in comparison with newborns the length of arteria increases by 7 times and the diameter grows by 2.0 times (table 1 ).

Arteries of reindeer's wrist start from the medial and radial. Most arteries are located in palmar and medial surfaces of the wrist.

In the region of metacarpus there are four arterial lines, three of them are located on the palmar surface, and one of them is located on the dorsal surface. Palmar metacarpal arteries are located on three different levels; 1) superficially under skin, and with a general fascia, the superficial palmar branch goes; 2) deeper, along medial border of interosseous muscle, the second palmar 
superficial metacarpal arteria goes; 3) the deepest line is

formed by the third deep metacarpal arteria.

Table 1. Age changes in the length and diameter of the arteria mediana for the northern reindeer

\begin{tabular}{|c|l|c|c|c|c|c|c|c|}
\hline No. & \multicolumn{1}{|c|}{$\begin{array}{c}\text { Age (months, } \\
\text { years) }\end{array}$} & $\mathrm{n}$ & Length $(\mathrm{cm})$ & $\begin{array}{c}\text { Relative } \\
\text { growth (in \%) }\end{array}$ & $\begin{array}{c}\text { Growth } \\
\text { coefficient }\end{array}$ & $\begin{array}{c}\text { Diameter } \\
\text { (in mm) }\end{array}$ & $\begin{array}{c}\text { Relative growth } \\
\text { (in \%) }\end{array}$ & $\begin{array}{c}\text { Growth } \\
\text { coefficient }\end{array}$ \\
\hline 1 & 1-3 days & 3 & $10.7 \pm 0.21$ & 5.9 & 1.05 & $2.0 \pm 0.14$ & 5.2 & 1.05 \\
\hline 2 & 1 month & 3 & $11.4 \pm 0.10$ & 6.5 & 1.06 & $2.3 \pm 0.19$ & 15.0 & 1.15 \\
\hline 3 & 6 months & 3 & $15.1 \pm 0.14$ & 32.4 & 1.32 & $3.1 \pm 0.11$ & 26.0 & 1.34 \\
\hline 4 & 12 months & 3 & $18.1 \pm 0.24$ & 19.8 & 1.19 & $3.6 \pm 0.10$ & 16.1 & 1.16 \\
\hline 5 & $3-3.5$ years & 3 & $20.1 \pm 0.28$ & 11.0 & 1.11 & $3.9 \pm 0.14$ & 8.3 & 1.08 \\
\hline 6 & 5-8 years & 3 & $20.7 \pm 0.16$ & 2.9 & 1.02 & $4.2 \pm 0.28$ & 7.6 & 1.07 \\
\hline 7 & Over the age of 10 & 3 & $20.7 \pm 0.35$ & 0 & - & $4.2 \pm 0.24$ & 0 & - \\
\hline 8 & Totally & 21 & & & & & & \\
\hline
\end{tabular}

In the area of each wrist finger there are one by one arterial lines. They start from the superficial palmar branch, which is divided into three vases in the distal third of wrist: general palmar finger-type the second, the third, and the fourth arteries. In return, the general palmar finger-type third arteria gives 2 round branches: axial native III and IV palmar finger-type arteries. From the general palmar finger-type second and fourth arteries, the arteries of lateral II and V fingers start.

In the distal third of wrist we identified surface and deep palmar arterial arches. The surface palmar arterial arch is formed by the surface palmar branch and the palmar surface second metacarpal arteria. The deep palmar arterial arch is formed by the palmar deep third metacarpal arteria, nutrimental arteria of metacarpal bone, and perforating distal metacarpal arteria.

On the off-centre surface of each finger (including lateral) the collateral paths of blood flow, which are formed by palmar branches of the first and second phalanxes, are detected.

The dorsal third metacarpal arteria starts from proximal metacarpal perforating arteria of wrist and goes down in the middle of dorsal surface of the metacarpal bone and accompanies namesake vein. From it the numerous twigs are departed to periosteum. The arteria, by the distal end of wrist, through interosseus hole connects with the palmar deep third metacarpal arteria, further it divides into two twigs that penetrate the articular torulus of metacarpal bone.

The surface palmar branch is a continuation of the arteria mediana on the wrist. It goes down along mediopalmar edge of sinews of the deep finger-type flexor between nerve mediana and the palmar surface second metacarpal arteria. The arteria with nerve mediana has general fibrous coat. At the top they are covered by the sinew of surface finger-type flexor. At the lower third of wrist the arteria enters the palmar surface of sinew for surface finger-type flexor and locates superficially under fascia and skin. In this area it gives the general palmar finger-type second and fourth arteries by lateral fingers. At the beginning the arteria goes to the second finger, and only then to the firth finger [5-8].

The length and diameter for adult reindeers are $16.6 \%$ and $4.8-4.9 \%$ of the length of liberal thoracic limb relatively. Morpho-metrical data, which is on the table No. 27, demonstrates that the length of arteries during postnatal period increases by 1.7 times; diameter of the arteries after birth by 2 times, while increase in diameter occurs before the age of 5 (table 2).

Higher absolute growth of arteria length is found in 1 month old calf $(3.3 \mathrm{~cm})$, newborn calves $(1.4 \mathrm{~cm})$, and then it decreases for 12 months old reindeers. After the age of 12 months arteria growth in length virtually terminates.

Absolute growth of arteria diameter in newborn calves from $0.3 \mathrm{~mm}$ to 0.1 for 12 months old reindeers. After the age of 12 month arteria growth in diameter virtually terminates.

Relative growth of the length is higher for newborn calves $(20.2 \%)$ and 1 month old youngsters $(36.1 \%)$. Then it decreases to $2.1 \%$ for 3 years old animals.

Relative growth of arteria breadth during postnatal period for 6 months old youngsters $(33.3 \%)$, then it decreases from 12 months old $(18.7 \%)$ to the age of 5 years of reindeers $(2.4 \%)$.

Growth coefficient of length for newborns $(1,20)$ and 1 month old calves (1.39). In other age groups of animals it varies from 1.02 to 1.12. Enlargement scale of arteria diameter is the highest for 6 months old youngsters (1.33). In other age groups it varies from 1.07 to 1.18 (table 26).

Growth rate of arteria length and diameter (for the age of 5 years) for newborn calves is 58.5 and $50.0 \%$, for 1 month old calves -81.7 and $57.1 \%, 6$ months old youngsters -91.5 and $76.2 \%, 12$ months old reindeers 97.2 and $90.5 \%$, for 3 years old reindeers -99.3 and $97.6 \%$.

Relative length and diameter of arteria to the length of liberal thoracic limb for 5 years old reindeers are 14.3 and $4.6 \%$ relatively.

Relative length of the surface palmar branch to the length of liberal limb for 1 month old calves (19,3\%), then, starting with 6 months old, it gradually decreases to $16,3 \%$ (for reindeers above 10 years of age).

Relative arteria breadth to length of liberal limb for newborn calves is up to $4.9 \%$, then for 1 month old calves it decreases up to $4 \%$, further it gradually increases up to $4.9 \%$ for 5 years old reindeers and remains on this level for old reindeers.

Superficial metacarpal arteria goes with median nerve to general fibrous case. Then it goes down along with their medial border of finger flexor's tendons in the region of the lower third of metacarpal bone and there it connects with the deep palmar metacarpal arteria and when it gives to finger's palmar arteria it reaches general palmar arteria of the main fingers. After the birth of 
reindeers the length of arteries in comparison with newborn calves increases by 1.7 times and diameter of arteries grows by 2.1 times (table 1 ).

Table 2. Age changes in the length and diameter of superficial palmar branch

\begin{tabular}{|c|c|c|c|c|c|c|c|c|}
\hline No. & $\begin{array}{c}\text { Age } \\
\text { (months, years) }\end{array}$ & $\mathrm{n}$ & $\begin{array}{l}\text { Length } \\
(\mathrm{cm})\end{array}$ & $\begin{array}{l}\text { Relative growth } \\
\text { (in \%) }\end{array}$ & $\begin{array}{c}\text { Growth } \\
\text { coefficient }\end{array}$ & $\begin{array}{l}\text { Diameter } \\
\text { (in mm) }\end{array}$ & $\begin{array}{c}\text { Relative } \\
\text { growth (in } \\
\%)\end{array}$ & $\begin{array}{c}\text { Growth } \\
\text { coefficient }\end{array}$ \\
\hline 1 & 1-3 days & 3 & $8.3 \pm 0.14$ & 20.2 & 1.20 & $2.1 \pm 0.12$ & 16.6 & 1.16 \\
\hline 2 & 1 month & 3 & $11.6 \pm 0.14$ & 36.1 & 1.39 & $2.4 \pm 0.17$ & 14.2 & 1.14 \\
\hline 3 & 6 months & 3 & $13.0 \pm 0.16$ & 12.0 & 1.12 & $3.2 \pm 0.21$ & 33.3 & 1.33 \\
\hline 4 & 12 months & 3 & $13.8 \pm 0.18$ & 6.1 & 1.06 & $3.8 \pm 0.10$ & 18.7 & 1.18 \\
\hline 5 & $3-3.5$ years & 3 & $14.1 \pm 0.11$ & 2.1 & 1.02 & $4.1 \pm 0.08$ & 7.8 & 1.07 \\
\hline 6 & $5-8$ years & 3 & $14.2 \pm 0.12$ & 0 & 1.00 & $4.2 \pm 0.14$ & 2.4 & 1.02 \\
\hline 7 & Over the age of 10 & 3 & $14.0 \pm 0.28$ & 0 & - & $4.2 \pm 0.37$ & 0 & - \\
\hline
\end{tabular}

Arteria metacarpea palmaris III is direct continuation of arteria mediana in the region of metacarpus after crossing of the last wrist joint. It lies on palmar surface of deep finger flexor's tendon and goes along sagittalis line of metacarpus. Along from the line there are no branches for muscles due to vascularisation of finger flexors which is effected by branches of the great vessels that are spread in the region of forearm. Only on the level of distal third of metacarpus bones from the third palmar metacarpal arteria there is separating arcual branch which is directed under the third interosseous muscle. Here it anastomoses with deep palmar branch which separates from arteria radialis. At this rate there forms deep palmar arc. After the birth of reindeers the length of arteries in comparison with newborn calves increases by 1.6 times and diameter of arteries grows by 2.4 times (table 1 ).

Arteria metacarpea palmaris II is continuation of arteria radialis in the region of metacarpus. It goes along mediopalmar border of metacarpus, accompanied with the general palmar metacarpal medial vein. Further by the lower edge of metacarpus it sides with superficial palmar branch. After the birth of reindeers the length of arteries in comparison with newborn calves increases by 1,8 times and diameter of arteries grows by 1.6 times (table 1).

Deep palmar metacarpal arteria goes down on medial border of interosseous muscle's tendon by the distal third of metacarpal bone it sides with superficial metacarpal arteria $[3,9]$.

Deep palmar metacarpal arteria mediana separates from medial-radial arteria in the region of proximal end of metacarpal bone it separates 2-3 branches for proximal epiphysis of metacarpal bone and joint capsule then it goes down on osseous vallecula under deep palmar medial metacarpal vein $[4,5,9,10]$.

General palmar arteries of main fingers go after separation of palmar arteria of the second finger. Then it goes down distally to superficial finger flexors - slightly lower than the arteria of the forth finger, from there it separates palmar arteria of the fifth finger in the region of fetlock joint.

Palmar arteries of the forth finger separate from general palmar arteria of main fingers. Then it goes along palmar border of the fifth finger and reaches the third maniphalanx $[4,5,9,11]$.

\section{Conclusion}

Thereby, according to the received data, we discovered that the highest increase of the length and diameter of arteries during postnatal period in the region of scapular waist occur until six month old.

In the region of the shoulder the main growth of the length and cross-section of arteria after the birth continues up to the age of three.

Maximal increase of the length and diameter of arteries in the region of forearm from the moment of birth continues until the age of five for the reindeer.

As for the third part of limbs maximal increase of the length and diameter of arteries continues until the age of three during postnatal ontogenesis.

\section{References}

1. K.S. Kirikov, Herald of Russian academy of agricultural sciences, 5, 44-45 (2014)

2. K.S. Kirikov, Herald of Russian academy of agricultural sciences, 4, 62-63 (2013)

3. V.A. Lisovichenko, I.B. Duguchiev, Hippology, 28 (2014)

4. V.A. Lisovichenko, Arteries in wrist of the northern reindeer (1999)

5. N.V. Zelenevskiy, et al., International veterinary anatomic nomenclature (Lan, St. Petersburg, 2013)

6. M.S. Potapov, K.S. Kirikov, S. Fedotov, K.R. Nifontov, N.A. Struchkov, In Emerging Threats for Human Health Impact of Socioeconomic and Climate Change on Zoonotic Diseases (2018)

7. N. Sato, Microvasc. Res., 33(1), 194-210 (1991)

8. N. Vazquez, D. dos Santos, W. Pérez, Anatom. Sci. int., 93.4, 540-547 (2018)

9. A.I. Akaevskiy, Anatomy of a reindeer (Ripol Classic, 2013)

10. T. Koch, Lehrbuch der Veterinar-anatomie - Jena, 2 (1970)

11. K.R. Nifontov., Int. herald of veter., 1, 23-26 (2013) 